This item was submitted to Loughborough's Research Repository by the author.

Items in Figshare are protected by copyright, with all rights reserved, unless otherwise indicated.

\title{
Specific Absorption Rates in the human head due to circular metallic earrings at $1800 \mathrm{MHz}$
}

PLEASE CITE THE PUBLISHED VERSION

PUBLISHER

(c) Loughborough University

LICENCE

CC BY-NC-ND 4.0

REPOSITORY RECORD

Whittow, W.G., C.J. Panagamuwa, R.M. Edwards, and J.C. Vardaxoglou. 2019. "Specific Absorption Rates in the Human Head Due to Circular Metallic Earrings at 1800mhz". figshare. https://hdl.handle.net/2134/2951. 
This item was submitted to Loughborough's Institutional Repository by the author and is made available under the following Creative Commons Licence conditions.

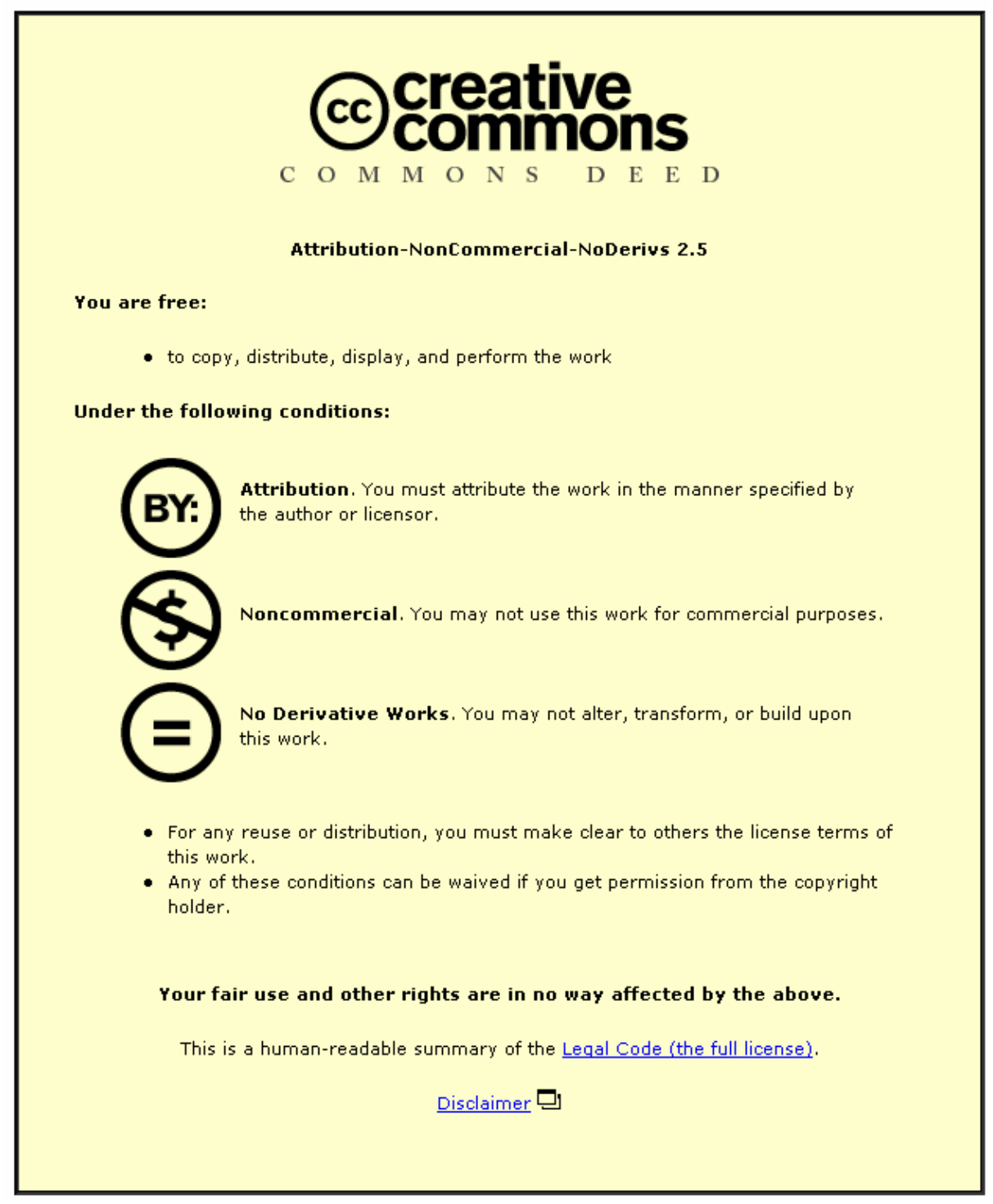

For the full text of this licence, please go to: http://creativecommons.org/licenses/by-nc-nd/2.5/ 


\title{
SPECIFIC ABSORPTION RATES IN THE HUMAN HEAD DUE TO CIRCULAR METALLIC EARRINGS AT 1800MHZ
}

\author{
W. Whittow (1), C. J. Panagamuwa (1), R. Edwards (1) and J. C. Vardaxoglou (1) \\ (1) Department of Electronic \& Electrical Engineering, Loughborough University, \\ Leicestershire, LE11 3TU. UK. \\ Email:W.G.Whittow@lboro.ac.ukEmail:C.J.Panagamuwa@lboro.ac.uk \\ Email: R.M.Edwards@lboro.ac.ukEmail: J.C.Vardaxoglou@lboro.ac.uk
}

\begin{abstract}
This paper investigates Specific Absorption Rates (SAR) in the human head due to circular metallic earrings at $1800 \mathrm{MHz}$. A Finite-Difference Time-Domain (FDTD) code was used to analyse different sizes and positions of circular earrings near a homogenous cubic phantom. Results showed good agreement with measurements using the flat section of the SAM twin phantom with the DASY4 measurement system. The excitation was a half wave dipole. Metallic loops with a circumference of approximately one wavelength and positioned $14 \mathrm{~mm}$ away from the phantom increased the $10 \mathrm{~g}$ SAR by 5 times. The FDTD code has also been used to analyse the effect of metallic earrings when 'pierced' through the ear of an anatomically realistic digital human head based on the Visible Human Project. The head is not symmetric and both ears were considered to allow comparison between different heads. The shape of the ear and the size of the earring were found to be very significant when earrings were hung from the human ear.
\end{abstract}

\section{Introduction}

There is concern that the radiation from mobile phones may adversely affect human health. In previous works, the authors [1] [2] have found that metallic spectacles can significantly increase the SAR in the eyes and head. It is commonly estimated that there are a billion mobile phone users in the world. Many of these may also wear metallic jewellery or have metallic objects in close proximity to their head. This includes facial piercings, metallic spectacles, jewellery on the hands, hairclips and bluetooth microphones. For clarity metallic objects in this paper are limited to metallic loops hung from the ear. A rigorous FDTD model is used to model a CW source positioned by the ear.

In recent years, work has been presented regarding mobile phones positioned near the ear [3] [4]. See [1] for a more complete review of bioelectromagnetics and the effect of metallic objects.

The authors [5] have previously researched the effect of metallic jewellery positioned in front of the face and excited with a communications enabled personal digital assistant device. Fayos-Fernandez [6] found metallic earrings increased the SAR using a dipole source positioned by the ear. He considered arcs, pins and small metallic studs. Recently, Virtanen [7] found that metallic implants inside the head could increase the SAR. He investigated metallic loops and pins inside a cylindrical head. Tay [8] has investigated the change in radiation efficiency using a passive reflector and directive element. He found that the efficiency could be increased if a metallic scatterer was positioned near to the dipole.

Troulis [9] used the FDTD method to briefly examine thin metallic spectacles on a heterogeneous phantom with a resolution of $5 \mathrm{~mm}$. The excitation used was a monopole on a metallic box positioned at the side of the head. The paper showed that metallic spectacles can re-distribute the energy produced by the cell phone's antenna, causing the efficiency to drop and the peak SAR to increase. Anderson [10] performed measurements with a phantom wearing metallic spectacles. With phones operating at $835 \mathrm{MHz}$, held by the ear, the SAR in the eye closest to the phone was found to increase by up to $29 \%$. Wang [11] modelled a monopole on a metallic box positioned by the ear of a human head wearing spectacles at $1500 \mathrm{MHz}$ using the FDTD method. In the same area, the effect on SAR in geometric and anatomical heads by nearby metallic walls [12] [13] and metallic implants [14] [15] has also been investigated.

\section{Description of model}

An independent 3D FDTD code [1] [2] has been written. Perfectly Matched Layers (PML) absorbing boundary conditions are used to terminate the grid. The PML is eight cells thick and is positioned at least twelve cells 
from the head. The Yee cell size used throughout this paper is $2 \mathrm{~mm}$. The lowest number of cells per wavelength was always greater than ten, and reasonable results have been obtained with only four [3].

To allow comparison between simulations and measurements, a dipole model has been used. The dipole is fed at its centre with a sinusoidal CW source. The tangential E-field components are set to zero along the length of the dipole [1]. All results in this paper are normalised to $1 \mathrm{~W}$ input power and the frequency of excitation is $1800 \mathrm{MHz}$. The dipole in the FDTD simulations is $74 \mathrm{~mm}$ long.

The metallic loops were modelled using metallic Yee cells, by setting the conductivity of the cells equal to the conductivity of copper [1]. Bernardi [13] used this technique to model metal shapes. Wang [11] modelled metallic spectacles by setting the conductivity of the Yee cells in the frames equal to titanium. The earrings investigated in this report were $2 \mathrm{~mm}$ thick ( 1 Yee cell) and of different diameters.

The results in this paper used a $200 \mathrm{~mm}$ cubic homogenous head, $40 \mathrm{~mm}$ away from the dipole. The properties of the brain simulating tissue of the homogeneous head are $\left(\sigma=1.37 \mathrm{~S} / \mathrm{m}, \varepsilon r=40.48, \rho=1000 \mathrm{~kg} / \mathrm{m}^{3}\right)$. The brain fluid is surrounded by a $2 \mathrm{~mm}$ thick fibreglass shell $(\sigma=0 \mathrm{~S} / \mathrm{m}, \varepsilon r=3.5)$. The advantage of using a cubic head is that the metallic jewellery is a constant distance from the head and the simulation results can be compared with DASY4 measurements made with the flat section of the SAM twin phantom [16]. The length of the dipole used in the measurements was $72.5 \mathrm{~mm}$ and had a diameter of 3.66mm [5], see Fig. 1.

Metallic jewellery has also been added to an anatomically realistic head. An adult male head matrix provided by Brooks Air Force was used (http://www.brooks.af.mil/AFRL/HED/hedr/hedr.html) [1]. The head is based on The Visible Human Project and has 25 tissue types. The head data has a $2 \mathrm{~mm}$ resolution. The densities and dielectric properties of the tissues in the Brooks head at $1800 \mathrm{MHz}$ are shown in [2]. SAR is the standard criteria to measure the amount of electromagnetic energy absorbed in the body and is calculated as in Eq. 1.

$$
S A R=\frac{\sigma|E|^{2}}{\rho} \quad(\mathrm{W} / \mathrm{kg})
$$

Where $|E|$ is the rms magnitude of the electric field strength vector, $\rho$ is the mass density of the material in $\mathrm{kg} / \mathrm{m}^{3}$ and $\sigma$ is the electrical conductivity in S/m. The SAR is calculated with the twelve-field approach [1].

\section{Results}

Initially, the FDTD code was used to search for the maximum effects of adding a metallic circular ring near to the homogeneous cubic phantom. The dipole was positoned $40 \mathrm{~mm}$ from the surface of the fibreglass shell. The centre of the dipole was placed below the centre of the loop, see Fig. 1 for the equivalent measurement setup. The results are shown in Fig. 2 for different sizes of loop at different distances from the cube. There was negligible increase in the $1 \mathrm{~g}$ SAR when the loop was touching the surface for all the sizes of loop investigated. The loop began to have a significant effect as it was moved away from the surface. The largest 1 and $10 \mathrm{~g}$ SAR values were found with the loop 12 to $16 \mathrm{~mm}$ away from the cube and when the circumference of the loop was approximately one wavelength.

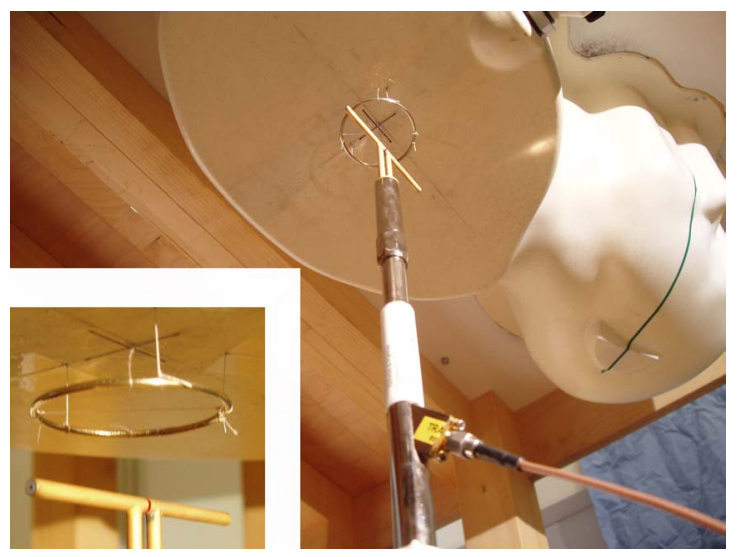

Figure 1. A circular ring and dipole positioned under the flat section of the SAM twin phantom.

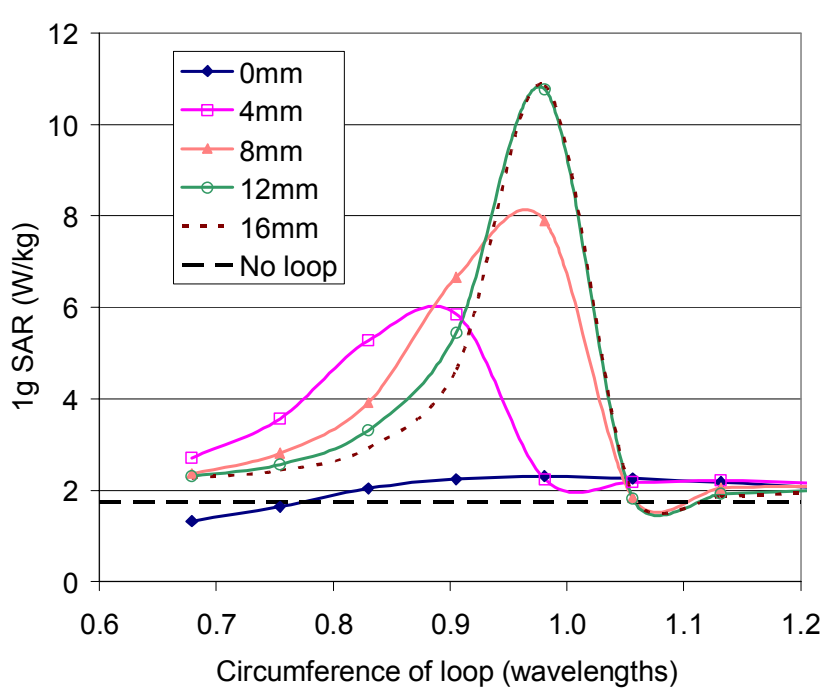

Figure 2. FDTD simulations of different sized loops at different distances from a cubic phantom. 
A loop with an external diameter of $52 \mathrm{~mm}$ and positioned $14 \mathrm{~mm}$ from the phantom produced the highest $1 \mathrm{~g}$ SAR. This combination was used to measure the SAR in the flat section of the SAM twin phantom using the DASY4 measurement system [16], see Fig. 1. The results for the 1 and 10g SAR for the measurements and simulations along with Microstripes commercial software [17] are shown in Table 1.

Table 1. The 1 and $10 \mathrm{~g}$ SAR in a flat/cubic phantom with a $52 \mathrm{~mm}$ diameter loop, $14 \mathrm{~mm}$ from the surface.

\begin{tabular}{|c|c|c|c|c|c|c|}
\hline & $\begin{array}{c}\text { FDTD } \\
\text { No loop }\end{array}$ & $\begin{array}{c}\text { DASY4 } \\
\text { No loop }\end{array}$ & $\begin{array}{c}\text { Microstripes } \\
\text { No loop }\end{array}$ & $\begin{array}{c}\text { FDTD } \\
52 \mathrm{~mm} \text { loop }\end{array}$ & $\begin{array}{c}\text { DASY4 } \\
52 \mathrm{~mm} \text { loop }\end{array}$ & $\begin{array}{c}\text { Microstripes } \\
52 \mathrm{~mm} \text { loop }\end{array}$ \\
\hline $1 \mathrm{~g}$ SAR $(\mathrm{W} / \mathrm{kg})$ & 1.74 & 1.70 & 1.60 & 11.03 & 10.23 & 10.09 \\
\hline $10 \mathrm{~g}$ SAR $(\mathrm{W} / \mathrm{kg})$ & 1.05 & 1.06 & 1.09 & 5.73 & 5.71 & 5.97 \\
\hline
\end{tabular}

The results in Table 1 show that a metallic ring can significantly increase the SAR in the head. The 52mm diameter ring, $14 \mathrm{~mm}$ from the cube increased the 1 and $10 \mathrm{~g}$ SAR by more than five times. Table 1 shows there is good agreement between the simulations, measurements and commercial software. The maximum SAR values were not found at the centre of the ring but occured by the edges of the ring on either side of the dipole.

Circular earrings were also added to an anatomically realistic digital human head. The head is not symmetric and so earrings were added to each ear seperately. The earring pierced the ear in the model. This meant the bottom cell of the ear was replaced by the metallic loop, see Fig. 3. The earrings hung down beside the head. The centre of the dipole was positioned $40 \mathrm{~mm}$ away from the top of the ring, see Fig. 3 .

The results of different circumferences of earring are shown in Fig. 4. Earrings can increase the $1 \mathrm{~g}$ SAR by 3.5 times in the anatomical head. The ears are different shapes and therefore the same earring may bahave differently on different ears. The close proximity of the head caused the ring to produce the largest $1 \mathrm{~g}$ SAR values when the circumference was approximately $0.65 \lambda$ not $\sim 1 \lambda$. A similar phenomen was also found with the cubic head, see Fig. 2. The effect of the earring on the $10 \mathrm{~g}$ SAR was not as significant and the range of ring sizes investigated had negligible effect on the $10 \mathrm{~g}$ SAR when the loop was by the right ear.

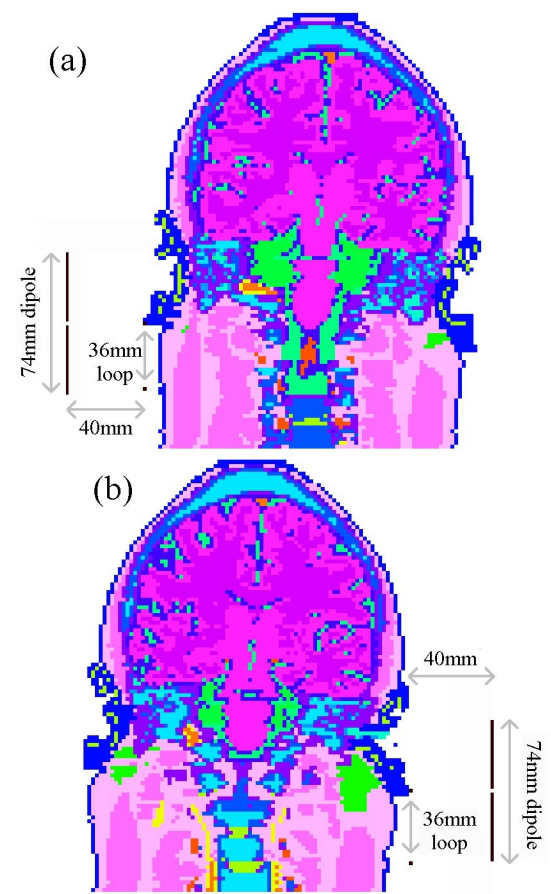

Figure 3. $74 \mathrm{~mm}$ dipole $40 \mathrm{~mm}$ from left (a) and right (b) ears of Brooks head with circular earring.

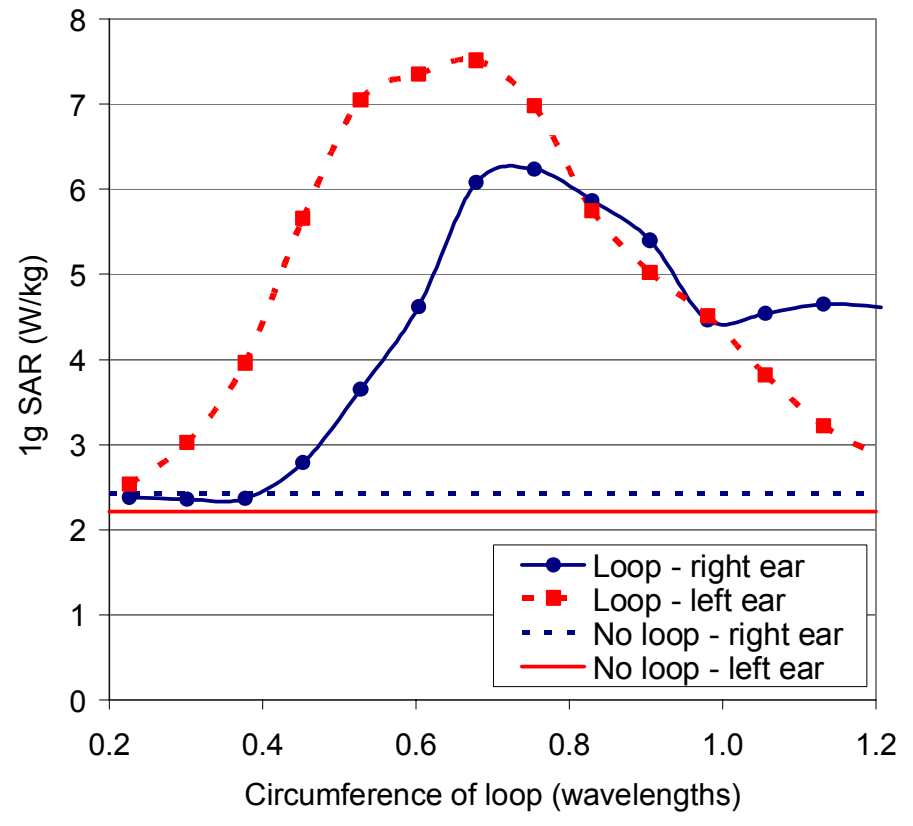

Figure 4. FDTD results of adding circular rings of different sizes to either side of the Brooks head.

\section{Conclusions}

The FDTD method was used to investigate the SAR in the presence of circular metallic earrings. The earrings caused the largest SAR in the head when the ring was approximately 1 wavelength in circumference and 
positioned away from the cube. Simulations agreed well with measurements. Metallic earrings produced smaller but still significant increases in the SAR in an anatomical model of a human head. The geometry of the ear and the surrounding tissues were found to be very important in detirmining the effects of the earring. The amplitude of the SAR and the resonance size of the ring can vary from ear to ear. Therefore, it may be difficult to investigate the effects on different people and a homogeneous cubic phantom may represeent a worst case scenario for the effects of metallic circular earrings.

\section{References}

[1] W. G. Whittow and R. M. Edwards, "A study of changes to specific absorption rates in the human eye close to perfectly conducting spectacles within the radio frequency range 1.5 to 3.0GHz.," IEEE Trans. Antennas and Propagation, vol. 52, pp. 3207-3212, 2004.

[2] W. G. Whittow and R. M. Edwards, "Applications of a genetic algorithm for identification of maxima in specific absorption rates in the human eye close to perfectly conducting spectacles," IEE Proceedings Science, Measurement \& Technology, vol. 152, pp. 89-96, 2005.

[3] A. D. Tinniswood, C. M. Furse, and O. P. Gandhi, "Computations of SAR distributions for two anatomically based models of the human head using CAD files of commercial telephones and the parallelized FDTD code," IEEE Transactions on Antennas and Propagation, vol. 46, pp. 829-833, 1998.

[4] P. J. Dimbylow and S. M. Mann, "SAR calculations in an anatomically realistic model of the head for mobile communication transceivers at 900-MHz and 1.8-GHz," Physics in Medicine and Biology, vol. 39, pp. 1537-1553, 1994.

[5] W. Whittow, C. J. Panagamuwa, R. Edwards, J. C. Vardaxoglou, and P. McEvoy, "A study of head worn jewelry, mobile phone RF energy and the effect of differing tissue types on rates of absorption," in The First European Conference on Antennas and Propagation (EuCAP 2006), Nice, France, 2006.

[6] J. Fayos-Fernandes, C. Arranz-Faz, A. Martinez-Gonzalez, and D. Sanchez-Hernandez, "Effect of pierced metallic objects on SAR distributions at 900MHz," Bioelectromagnetics, vol. 27, pp. 337-353, 2006.

[7] H. Virtanen, J. Huttunen, A. Toropainen, and R. Lappalainen, "Interaction of mobile phones with superficial passive implants," Physics in Medicine and Biology, vol. 50, pp. 2689-2700, 2005.

[8] R. Tay, Q. Balzano, and N. Kuster, "Dipole configurations with strongly improved radiation efficiency for hand-held transceivers," IEEE Trans. Antennas and Propagation, vol. 46, pp. 798-806, 1998.

[9] S. E. Troulis, W. G. Scanlon, and N. E. Evans, "Effect of 'hands-free' leads and spectacles on SAR for a $1.8 \mathrm{GHz}$ cellular handset.," in 1st Joint IEI / IEE Symposium on Telecommunications Systems Research, Dublin, 2001, pp. 1675-1684.

[10] V. Anderson and K. H. Joyner, "Specific absorption rate levels measured in a phantom head exposed to radiofrequency transmissions from analog hand-held mobile phones," Bioelectromagnetics, vol. 16, pp. 60-69, 1995.

[11] J. Wang, T. Joukou, and O. Fujiwara, "Localized specific absorption rate in the human head in metalframed spectacles for 1.5GHz Hand-held mobile telephones," Trans IEE of Japan, vol. 118-A, pp. 1234-1240, 1998.

[12] J. Cooper and V. Hombach, "The specific absorption rate in a spherical head model from a dipole with metallic walls nearby," IEEE Transactions on Electromagnetic Compatibility, vol. 40, pp. 377-382, 1998.

[13] P. Bernardi, M. Cavagnaro, and S. Pisa, "Evaluation of the SAR distribution in the human head for cellular phones used in a partially closed environment," IEEE Transactions on Electromagnetic Compatibility, vol. 38, pp. 357-366, 1996.

[14] J. Cooper and V. Hombach, "Increase in specific absorption rate in humans from implantations," Electronic Letters, vol. 32, pp. 2217-2219, 1996.

[15] R. McIntosh, V. Anderson, and R. Mckensie, "A numerical evaluation of SAR distribution and temperature changes around a metallic plate in the head of a RF exposed worker," Bioelectromagnetics, vol. 26, pp. 377-388, 2005.

[16] T. Schmid, O. Egger, and N. Kuster, "Automated E-field scanning system for dosimetric assessments," IEEE Microwave Theory and Techniques, vol. 44, pp. $105-113,1996$.

[17] Flomerics, "Micro-Stripes Reference Manual, Release 7.5," 2006. 